\title{
CONVERSAS ENTRE ESCHER E DELEUZE: TECENDO PERCURSOS PARA SE PENSAR A SUBJETIVAÇÃO
}

\author{
Andréia Machado Oliveira \\ Tania Mara Galli Fonseca \\ Universidade Federal do Rio Grande do Sul
}

RESUMO: Este texto busca visualizar configurações espaciais e temporais que subvertam estruturas lineares e dicotômicas através de formas de ocupação do espaço construídas na multiplicidade. Tal visualização incidirá a partir das obras do artista plástico Murits Escher (1898-1972) com aproximações de alguns conceitos trabalhados por Gilles Deleuze (1925-1995). Considera-se que o encontro desses referenciais provindos da Arte e da Filosofia contribuem para a tessitura de percursos para a problematização de outros modos de subjetivação. A obra de Escher é um questionar sobre a realidade através dos seus próprios elementos configurados de formas surpreendentes e inconcebíveis, uma vez que desarticulam o estabelecido.

PALAVRAS-CHAVE: subjetivação; multiplicidade; perspectivismo.

\section{COLLOQUIES BETWEEN ESCHER AND DELEUZE: WEAVING PASSAGEWAYS FOR THINKING ON SUBJECTIVENESS}

ABSTRACT: This text aims to visualize spatial and temporal configurations that breach linear and polarized structures through ways of occupying constructed space in multiplicity. Such visualization will take place from the art works of Murits Escher (1898-1972) with approaches of some concepts of Gilles Deleuze (1925-1995). The meeting of these references from Art and Philosophy is considered a contribution in weaving passageways for querying other forms of subjectiveness. Escher's art work is a questionnaire on reality through its own configured elements of surprising and inconceivable forms, once they disarticulate that which is established.

KEYWORDS: subjectiveness; multiplicity; perspectivism.

As configurações construídas por Escher abrigam jogos de ilusão que suportam o impensado, a diferença e o paradoxo. Estas configurações constituem corpos que configuram paisagens, bem como, paisagens que contornam corpos: jogos que Escher propõe gerando uma paisagemcorpo e um corpo-paisagem que inquirem outros modos de subjetivação. São delineações sobre as quais o plano da vida se trama e o tempo se imprime por meio das inscrições interiores e exteriores das dobras, dos fluxos e densidades das forças, ou seja, estes sutis registros corporais, gravados no viver, mapeiam paisagens que explicitam os tempos em que se desdobram, as forças que as atravessam, as relações que as determinam e os seres que a habitam.

Deste modo, este corpo constituído como lugar de habitação, apresenta-se aberto a um jogo de realidades plásticas que incita ao deslocamento e aos percursos inusitados das paisagens. As construções de Escher nos fazem indagar que relações estão potencializadas naquelas paisagens que causam vertigens, e que outros modos possíveis de ocupação e circulação elas desafiam. Questionam a veracidade do lugar que o sujeito ocupa investigando o instante do olhar que abre à perspectiva do paradoxo e aos múltiplos trajetos possíveis de percorrer. Exploram como se dão os encontros, as misturas, as passagens das realidades neste lugar que não converge ao mesmo ponto nem comporta posições polarizadas e binarizadas.
Escher estabelece lugares que nos causam estranhamento, sobretudo sobre os lugares que nós próprios ocupamos, uma vez que estes se mostram tão rígidos, unidirecionais e autoritários perante as alternativas propostas por ele. Ao trabalhar com técnica de gravura, Escher não grava estes lugares apenas sobre as matrizes, mas sobre o nosso imaginário carente de representações que permitam o lúdico, os jogos sem hierarquias nem dominações fixas. O modo de objetivação do mundo reflete-se no próprio modo de subjetivação como seu avesso e duplo adquirindo ambos uma espessura plástica contraposta a um modelo dominante. Nestas composições todos os termos são valorizados no seu alto grau de potência, uma vez que implica em uma conexão tensa entre percepção e ação, estabelecendo-se um agenciamento, um acoplamento. Escher cria relações de composição a partir de um paradigma éticoestético, já que consiste em criar estratégias de produção de conhecimento em que coexistem o ser, o tempo e o espaço, formados no mesmo processo e produzindo modos de subjetivação que não dizem respeito ao sujeito em si e não pré-existem a ele como verdade universal.

A porta pela qual entramos nas composições de Escher é o prazer da descoberta. Segundo Bruno Ernst, em seu livro O espelho mágico de Escher (1991), sua obra é embrionada e movida pela descoberta que o fascinava: "Para um primeiro conhecimento basta só conseguir que cada 
observador se convença de que a "compreensão" da obra, está ligada ao prazer duma descoberta. Este prazer é o centro da própria inspiração de Escher - transmiti-lo foi objetivo e fim de sua arte" (1991, p. 16). Como o próprio Escher (in Ernst, 1991, p. 14) nos diz:

Nunca quis representar nada místico; o que muitos chamam de misterioso, não é mais do que uma ilusão consciente ou inconsciente! Joguei um jogo, senti gozo em pensar imagens sem nenhuma outra intenção do que a de investigar a possibilidade da sua representação. Tudo o que ofereço nas minhas gravuras são relatórios das minhas descobertas.

A descoberta é a chave do jogo que Escher propõe a partir da ilusão, como se ele brincasse com espelhos e colocasse as ilusões umas sobre as outras, fazendo com que uma ilusão somente possa ser desvendada a partir da outra, ou seja, a ilusão pode ser vista como a fresta de passagem para seus mundos não imagináveis.

Estas ilusões atreladas à realidade nos remetem a construções surrealistas. Porém, não se trata de um surrealismo que nos coloca em um enigma; ao contrário, nos explicita a sua solução. Escher cria mundos não-existentes de forma inusitada, nos mostra “outra coisa”, o próprio não pensado a partir do estranhamento ao familiar. Deste modo, não silencia a razão, mas a utiliza para intervir na construção de mundos que atentam para outros modos de subjetivar o olhar. Um olhar que admite inúmeros mundos coexistindo ao mesmo tempo e num só lugar, num só plano de representação. Um olhar perspectivo que abrange multiplicidade de realidades possíveis e não definidas.

Escher nos faz ver o impossível que habita o possível. Não tem mais a ver com a representação fiel da realidade como uma unidade coerente, mas sim com ilusão óptica, com percepção de realidades múltiplas e simultâneas. Segundo Bruno Ernst (1991, p. 66):

Os mundos impossíveis de Escher são de outra espécie. Escher mostra-nos como uma coisa pode ser simultaneamente côncava e convexa; que as suas figuras podem andar no mesmo momento e no mesmo lugar, tanto escadas acima como escadas abaixo. Ele tornanos claro que uma coisa pode estar ao mesmo tempo tanto dentro como fora, ou quando ele usa escalas diferentes num desenho, existe uma lógica de composição que faz desta coexistência a coisa mais natural do mundo. Escher não é nenhum surrealista que, como por encanto, nos apresenta uma miragem. Ele é um construtor de mundos impossiveis. Ele constrói o impossivel rigorosamente segundo as leis e de tal forma, que qualquer um pode compreender; e nas suas gravuras não mostra só o resultado final, mas também o sistema de construção.

As imagens de Escher nos causam uma sensação de magia através de combinações não pensadas entre elementos habituais. Coisas, situações completamente impos- síveis são retratadas com relatividade, lógica e clareza, de tal modo que nos causam desacomodação e desconforto: o que é real ou não.

Em sua obra, pode-se observar a quebra com a idéia de unidade coerente e totalizadora sugerindo a existência de "eus" admissíveis, conforme haja realidades vivenciadas, ou seja, inúmeras realidades possíveis de acordo com quantos domínios de validação se tenham. Concebe uma multiplicidade formadora que ousa aceitar a fragmentalidade, o desencaixe, as contrariedades e os paradoxos. Ajuda-nos a pensar a questão da segmentaridade que constitui o ser, segmentaridade esta também investigada por Deleuze e Guattari (1996). Conforme vemos a seguir, em suas próprias palavras:

\begin{abstract}
Somos segmentarizados por todos os lados e em todas as direções. O homem é um animal segmentário. A segmentaridade pertence a todos os estratos que nos compõem. Habitar, circular, trabalhar, brincar: $o$ vivido é segmentarizado espacial e socialmente. A casa é segmentarizada conforme a destinação de seus cômodos; as ruas, conforme a ordem da cidade; a fábrica, conforme a natureza dos trabalhos e das operações. (1996, p.84) [...] Certamente, o centralizado não se opõe ao segmentário [...] A segmentaridade torna-se dura, na medida em que todos os centros ressoam, todos os buracos negros caem num ponto de acumulação [...] (Deleuze e Guattari, 1996, p.87).
\end{abstract}

A unidade e a segmentaridade são colocadas, de acordo com as propostas dos autores aqui correlacionados, de forma não binária nem excludente, já que uma sempre se encontra presente na outra. Todavia, ao incluírem a segmentaridade, rompem com uma unidade autoritária e castradora. Apontam a inexistência de apenas um modo de composição dos elementos formadores da realidade, demonstrando incontáveis formas de realidades. Explicitam que as realidades pertencem aos seus lugares espaciais e temporais, de modo que os sujeitos somente podem ser vistos com sua historicidade, uma vez que esta os constitui. Afirmam uma condição histórica do ser: composições de recortes transversalizados por tempos distintos.

Escher delata a limitação da nossa percepção de realidade diante da impossibilidade de apreender a coexistência do diverso, ou seja, o que nos parece estranho em suas imagens é a existência simultânea do diferente; sem hierarquias, sem início e fim, sem verdade e mentira, como ele próprio nos diz: "Vejam, eu mostro-vos algo que vocês não consideram possível” (Ernest, 1991, p.6). Nas litografias Relatividade (1953) e Em cima e em baixo ${ }^{2}$ (1947) Escher joga com a perspectiva, forma de representação espacial inquestionável desde o Renascimento, exceto pelo cubismo. Para Bruno Ernst (1991), na litografia Relatividade, observa-se três pontos de fuga, três realidades simultâneas, sendo que cada um destes três pontos tem três significações diferentes: 
as 16 figurinhas que aparecem na gravura podem ser divididas em três grupos, nos quais cada uma delas vive no seu próprio mundo. Para cada grupo, o seu mundo é tudo o que aparece na estampa; só que se apercebem das coisas de forma diferente $e$ lhes dão nomes diferentes. $O$ que é para um grupo um tecto, é para o outro uma parede; o que para uma comunidade é uma porta, é para a outra um buraco no chão (Ernest, 1991, p.47).

Escher oferece, com os jogos de perspectiva, um meio de visualização da relatividade que se contrapõe ao absoluto. Conceitos do cotidiano como em cima e em baixo, dentro e fora, são relativos e alterados; relações absolutamente novas a partir de elementos habituais apresentam mundos, ao mesmo tempo, estranhos e possíveis.

As estruturas de Escher, segmentarizadas e a-centradas, nos remetem ao plano rizomático concebido por Deleuze e Guattari (1995). Um rizoma, segundo eles, constitui-se de:

sistemas a-centrados, redes de autômatos finitos, nos quais a comunicação se faz de um vizinho a um vizinho qualquer, onde as hastes ou canais não preexistem, nos quais os indivíduos são todos intercambiáveis, se definem somente por um estado a tal momento, de tal maneira que as operações locais se coordenam e o resultado final global se sincroniza independente de uma instância central (Deleuze \& Guattari, 1995, p.27).

Planos nos quais qualquer ponto pode conectar com outro, configurando uma rede promíscua que se alastra, sem um ponto fixo, sem castas, sem ordem determinada, sem unidade fixa. São espaços constituídos por um princípio de multiplicidade que não busca unidade nem no sujeito nem no objeto, mas nos movimentos dos fluxos das redes que se configuram pelos agenciamentos entre sujeitos/objetos/lugares. Estes espaços, sem estrutura central, permitem construções desmontáveis e conectáveis que abrem ao finito ilimitado e às estruturas fractais, bem como, ao descentramento tanto do espaço quanto do sujeito que se dimensiona através de um perspectivismo.

Outra característica do rizoma, que se aproxima das construções de Escher, é a lógica do E que corresponde ao tecido de conjunção do rizoma. Esta lógica implica na coexistência do diferente e no acesso ao intermezzo, ao entre as coisas. Ela nos remete a um elemento fundamental das composições de Escher: a dualidade. Conforme Escher (in Ernest, 1991, p. 17) nos diz:

O Bem não pode existir sem o Mal e quando se aceita um Deus, então tem de se dar, por outro lado, um lugar equivalente ao Demônio. Isto é o equilíbrio. Vivo desta dualidade. Mas isso também não parece ser permitido. As pessoas tornam-se logo tão profundas sobre estas coisas, que em breve deixo completamente de perceber. Na realidade, porém, é muito simples: branco e preto, dia e noite - o gravador vive disso.
Este dualismo não deve ser visto como algo excludente, construído no ou/ou, mas como exigência para a existência de ambos de maneira complementar. Por exemplo, nas xilogravuras Limite Circular IV $V^{3}$ (1960), Dia e Noite $^{4}$ (1938) e Encontro ${ }^{5}$ (1944), visualiza-se essa relação de complementaridade fundamentada na simultaneidade de opostos e na mistura de mundos diferentes: a existência de uma figura é dada na ausência da outra. A existência de uma pressupõe a existência da outra, produzida pela sua ausência. Pode-se dizer que, através do dualismo, um jogo se arma e somos lançados nas ilusões fractais: movemonos em um espaço sem determinação a priori, tal como Alice no País das Maravilhas do filme Labirinto, ${ }^{6} \mathrm{com}$ David Bowie. Para compreender a obra de Escher é imprescindível um outro olhar, sem conotação moral sobre a vida. Olhar plástico, apenas um olhar.

A repetição também é um elemento gerador na obra de Escher: repetição que provoca o diferente e não reproduz o semelhante. Observa-se na obra Ar e Água $\Gamma$ (1938) e Metamorphose $^{8}$ (1939-1967) que as figuras em cada repetição sofrem pequenas mudanças, em um contexto próximo, alterações insignificantes na sua estrutura. Entretanto, com um olhar mais distanciado, nota-se que se transmutam em outras figuras. Os pequenos detalhes aos quais não se dá importância, por isso imperceptíveis nas experiências e nos fazeres, vão delineando a diferenciação. Como se o nosso olhar se detivesse em instantes estáticos e não percebesse as nuances dos movimentos constantes da duração: a dura ação de durar a ação, de nos diferenciarmos de nós mesmos. Remete as sutilezas da subjetivação que não se ata em determinações estanques, mas se leva pelo fluxo do devir que não cessa de invocar outras configurações.

Ainda se constata outro elemento construtor nas imagens de Escher: o paradoxo. A partir do laço de Moebius, ele investigou a temática do dentro e do fora em várias obras: Cavaleiros (1946), Laço de Moebius I (1961), Laço de Moebius II (1963), e Nós ( 1965). Estas xilogravuras demonstram o paradoxo do exterior/interior, do dentro/ fora nos fazendo indagar como se define o dentro e o fora? Como se separa a figura e o espaço, o sujeito e o social? Imagens sem início e fim mostram a impossibilidade de construir o dentro e o fora separadamente, uma vez que, quando se pensa que se está dentro, já se está fora e viceversa. Não existe separadamente o fora e o dentro, não há o ser de fora e o ser de dentro: é com o fora que o ser se forma, se interioriza e se dobra sobre si.

Este paradoxo também constitui o conceito de dobra de Deleuze (1986) que proporciona uma visão ininterrupção do dentro e do fora, do sujeito e do social. A subjetivação diz respeito aos diferentes modos de subjetividade no território social, não se limitando ao sujeito, mas aos acontecimentos que envolvem ou não os sujeitos, de forma singular e múltipla. Refere-se a um processo de trans- 
formação simultâneo do fora e do dentro que abole com um interior pessoal separado do social. Ao contrário, a interioridade se produz como um dobramento das forças do exterior. Na obra Galeria de Arte ${ }^{9}$ (1956), Escher constrói uma dobra espacial, localizando o sujeito de maneira que ele habita o dentro e o fora simultaneamente, assim permitindo questionar os limites entre mundo interior e exterior.

Finalizando, pode-se pensar Escher com a luz de Merleau Ponty ao colocar que uma obra por fazer exige uma determinada vida por viver. Suas obras são testemunhas e cúmplices de sua busca, que, segundo Escher (Escher apud Ernest, 1991, p.16), tinha uma dimensão indemonstrável: "Se soubessem só o que eu vi na escuridão da noite [...] fiquei por vezes louco de mágoa por o não poder representar. Em comparação com isso, é cada estampa um malogro que nem sequer reproduz uma fracção daquilo que deveria ser". O mergulho que Escher realiza na escuridão de cada noite e na procura de cada obra evidencia um processo construcionista que potencializa a vida pela imersão ao caos, pelas intensidades pulsantes nos acontecimentos no lugar das representações.

Em Escher, as perspectivas, as repetições, os paradoxos, as divisões de superfícies, as metamorfoses, são registros de sua vida. Esta conduzida pela paixão, como ele nos relata:

Enquanto estou ocupado com alguma coisa, penso que estou a fazer a coisa mais linda do mundo. Quando tenho êxito nalguma coisa, então à noite, sentome em frente dela enamorado. E essa paixão é maior do que qualquer paixão por pessoa. No dia seguinte, os olhos abrem-se de novo.... (Escher apud Ernst, 1991, p.18).

Remetendo-se aos conceitos de Deleuze, Escher se apresenta como um artista da fuga que se move pelos fluxos da paixão criando outros trajetos no plano vivido e produzindo modos de subjetivação abrigados na multiplicidade e na diferença.

\section{Notas}

1 "Relatividade", litografia, 1953, 28 x 29cm. Três planos de gravitação agem aqui verticalmente uns sobre os outros. Três superfícies terrestres, vivendo em cada uma delas seres humanos, intersectam-se em ângulo recto. Dois habitantes de mundos diferentes não podem andar, sentar-se ou ficar em pé no mesmo solo, pois sua concepção de horizontal e vertical não se conjuga. Eles podem, contudo, usar a mesma escada. Na escada mais alta das aqui representadas, movem-se, lado a lado, duas pessoas na mesma direcção. Todavia, uma desce e a outra sobe. É claramente impossível um contacto entre ambas, pois vivem em mundos diferentes e não sabem, portanto, da existência uma da outra." (Escher, 1989, p.15).

2 "Em cima e em baixo", litografia, 1947, 50,5 x 20,5 cm. Nesta estampa reproduz-se duas vezes a mesma representação, cada uma delas dum ponto de vista diferente. A metade superior mostra a vista de um observador que se encontre pela altura do segundo andar. A metade inferior, pelo contrário, mostra o cenário que ele veria do rés-do-chão. Se ele daqui dirigir o olhar para cima, verá o ladrilho, sobre o qual se encontra, no centro da composição, repetido como tecto." (Escher, 1989, p.15).

3 "Limite circular IV (Céu e Inferno)", xilogravura, prova de duas matrizes, 1960 , com diâmetro de $41,5 \mathrm{~cm}$. Também aqui, as componentes se reduzem de dentro para fora. As seis maiores, três anjos brancos e três demônios pretos, estão ordenadas radialmente em volta do centro. O disco está dividido em seis sectores, onde dominam os anjos, frente a um fundo preto e os demônios, frente a um branco. Céu e Inferno aparecem alternadamente seis vezes. Nos estádios "terrestres" intermédios são equivalentes" (Escher, 1989, p.10).

4 "Dia e Noite", xilogravura, prova de duas matrizes, 1938, 39 x $68 \mathrm{~cm}$. Campos cinzentos rectangulares evoluem para cima, em silhuetas de aves brancas e pretas. Como duas formações de sentido contrário, voam as pretas para a esquerda e as brancas para a direita. No lado esquerdo fundem-se as brancas umas nas outras e formam céu e paisagem de dia. Do lado direito, unem-se as pretas na noite. A paisagem do dia e da noite são imagens refletidas uma de outra, ligadas por campos cinzentos, dos quais de novo evoluem aves" (Escher, 1989, p.9).

5 "Encontro", litografia, 1944, 34 x 46,5 cm. A partir dos limites cinzentos duma parede traseira, desenvolve-se um complicado padrão de figuras humanas brancas e pretas. Como seres vivos que são, precisam, pelo menos, dum chão sobre o qual se possam mover. Foi para eles desenhado um, tendo no meio um buraco circular, de maneira a poder ver-se ainda, tanto quanto possível, a parede traseira. Assim, são obrigados a moverem-se em círculo e ao mesmo tempo a encontrarem-se no plano de frente: um optimista branco e um pessimista preto apertam as mãos" (Escher, 1989, p.11).

6 LABIRINTO. Direção de Jim Henson. Estados Unidos, 1986.

7 "Ar e água I", xilogravura, 1938, 44 x 44 cm. Na linha média horizontal estão peixes e aves em iguais condições. Mas com o vôo associamos o ar, por isso, para uma ave preta, os quatro peixes que a rodeiam são o ar em que ela voa. Do mesmo modo, associamos nadar com água, por isso as"quatro aves pretas que rodeiam um peixe tornam-se para este a água na qual ele nada" (Escher, 1989, p.9).

8 "Metamorfose", xilogravura, prova de 29 matrizes, 1939-40 e 1967-68, 19,5 x 700 cm. Uma longa sequiência de metamorfoses. [...] A torre que está na água é ao mesmo tempo uma figura de xadrez cujo tabuleiro, com seus quadrados claros e escuros, conduz às letras da palavra "metamorphose" (Escher, 1989, p.11).

9 "Galeria de arte", litografia, 1956, 32 x 32 cm. Como variação do tema da estampa "Varanda", produz-se aqui um alargamento circular em volta do centro vazio, no sentido dos ponteiros do relógio. [...] O jovem vê todas estas coisas como pormenores bidimensionais dum quadro que observa. Se o seu olhar ainda continuar a vaguear um pouco, ver-se-á ele próprio como parte do quadro" (Escher, 1989, p.16).

\section{Referências}

Deleuze, G. (1986). Foucault. Paris: Minuit.

Deleuze, G. \& Guattari, F. (1995). Mil platôs: capitalismo e esquizofrenia (Vol. I). Rio de Janeiro: Ed.34.

Deleuze, G. \& Guattari, F. (1996). Mil platôs: capitalismo e esquizofrenia (Vol. III). Rio de Janeiro: Ed.34. 
Oliveira, A.M.; Fonseca, T.M.G. "Conversas entre Escher e Deleuze: tecendo percursos para se pensar a subjetivação"

Deleuze, G. \& Guattari, F. (1997). Mil platôs: capitalismo e esquizofrenia (Vol. V). Rio de Janeiro: Ed.34.

Escher, M.C. (1989). M. C. Escher, gravuras e desenhos. Alemanha: Taschen.

Ernst, B. (1991). Oespelhomágico de M. C. Escher. Singapore: Taschen.

Andréia Machado Oliveira. Artista plástica e professora de História da Arte. Formação em Bacharelado e Licenciatura em Artes Visuais/UFRGS. Mestre em Psicologia Social e Institucional/UFRGS. Doutoranda em Informática da Educação/UFRGS. Pesquisadora dos

Grupos de Pesquisa "Modos de Trabalhar, Modos de Subjetivar" e "NESTA - Núcleo de Estudo sobre Subjetivação, Tecnologia e Arte"/UFRGS. Endereço para correspondência: Otto Niemeyer, 2417/115. Bairro Camaquã/POA/RS/BR. CEP: 91910-001. andreiao@cpovo.net
Tania Mara Galli Fonseca. Profa. Dra. Orientadora do Programa de Pós-graduação em Psicologia Social e Institucional e do Programa de Pós-graduação em Informática na Educação/UFRGS.

\section{Conversas entre escher e deleuze: tecendo percursos para se pensar a subjetivação}

Andréia Machado Oliveira e Tania Mara Galli Fonseca Recebido: 17/05/2005

$1^{a}$ revisão: 06/03/2006

Aceite final: 07/06/2006 